\title{
Prenatal diagnosis and preimplantation genetic diagnosis in hematological disorders - a preliminary data from India
}

\author{
Nair SB*, Athalye AS, Sanap RR, Warang DJ, Padyal PM, Madon PF and Parikh FR \\ Department of Assisted Reproduction and Genetics, Jaslok Hospital and Research Centre, Mumbai, India
}

\begin{abstract}
Hemoglobinopathies like $\beta$-thalassemia and sickle cell anemia are very prevalent in India. The only way of prevention of this severe genetic disorder is to identify the carriers and counsel them about the clinical severity of the disease and to create awareness about the options of prenatal diagnosis (PND) and Preimplantation genetic diagnosis (PGD). In this paper we report our experience on the PND and PGD in haematological disorders carried out at our centre, Jaslok Hospital in India.
\end{abstract}

\section{Introduction}

The inherited disorders of hemoglobin which include the thalassemia and the structural hemoglobin variant are the commonest group of autosomal recessively inherited single gene disorders globally $[1,2]$. Hemoglobinopathies like $\beta$-thalassemia and sickle cell anemia and its interaction with other hemoglobin variants like $\mathrm{HbE}$ and $\mathrm{Hb} \mathrm{S}$ poses a major health burden in India. Out of the 240 million carriers worldwide India alone has 30 million carriers [3]. With an overall prevalence of $3-4 \%$ of $\beta$-thalassemia carriers in India, it is estimated that there would be $30-40$ million carriers and 10,000 to 12,000 children with thalassemia major born each year [4]. Hemochromatosis is another hereditary metabolic disorder in which iron salts are deposited in the tissues, leading to liver damage, diabetes mellitus, and bronze discoloration of the skin.

Preventive strategies are therefore extremely important to control the disorder from passing on to the next generation. Identification of the traits or carriers of these disorders is an important aspect. Prenatal diagnosis (PND) or Preimplantation Genetic Diagnosis (PGD) forms an integral part of a community control programme for hemoglobinopathies [5].

PND can be offered to couple who are identified as carriers of the disorder from as early as 9-10 weeks of pregnancy through chorionic villus biopsy (CVS). If the fetus is found to be affected, then the pregnancy can be terminated early [6]. PGD is an alternative to PND to help couples avoid the emotional trauma of termination of affected pregnancies $[7,8]$.

PGD can be offered through an IVF cycle by choosing an unaffected embryo for transfer, thus providing couples a chance to start pregnancy with an unaffected fetus and avoiding termination of affected pregnancies [7,9]. Using PGD technology, HLA-matched embryos also can be chosen to cure an affected child in future by transplanting stem cells from cord and bone marrow from unaffected sibling [10,11]. Here we present a preliminary data on our experience on PND and PGD haematological disorders at Jaslok Hospital in India.

\section{Material and methods}

Prenatal diagnosis was offered to 9 couples for $\beta$-thalassemia and 1 couple for sickle cell anemia using amplified refractory mutation detection system (ARMS) PCR on chorionic villus sample. DNA extraction was done from the EDTA blood samples of the parents and fetal sample using Qiagen blood DNA extraction kit as per manufacturer's protocol. Molecular analysis of the beta globin gene for mutations was performed on DNA extracted from the fetal tissue by ARMS PCR followed by detection using agarose gel electrophoresis. Variable number of tandem repeat (VNTR) marker analysis was always carried out on all fetal samples to check for presence or absence of maternal cell contamination to avoid misdiagnosis.

PGD for $\beta$-thalassemia (4 couples, 6 cycles), sickle cell anemia (1 couple, 1 cycle) and hemochromatosis ( 1 couple, 1 cycle) was carried out at our center by embryo biopsy of trophectoderm cells during the IVF cycle. The mutations were analyzed using whole genome amplification followed by Sanger sequencing. Unaffected embryos were then used for transfer. All the successful pregnancies are again reconfirmed by PND to avoid misdiagnosis due to complete amplification failure, allelic dropout (ADO) or possibility of sample contamination.

Genetic counseling on the clinical severity of the disease, the inheritance pattern, reproductive options of both PND as well as PGD and the risks involved in these diagnosis procedures were explained to all the couples who came for testing.

\section{Results}

\section{Prenatal Diagnosis (PND)}

PND was offered for 9 couples who were detected as carriers of hemoglobinopathy on screening. After prenatal diagnosis, fetus was found to be affected in 5 of 9 couples for $\beta$-thalassemia. The couple who were sickle cell trait showed a heterozygous fetus. MCC testing was done and absence of MCC was confirmed in all these prenatal samples.

${ }^{\star}$ Correspondence to: Sona B. Nair, Department of Assisted Reproduction and Genetics, Jaslok Hospital and Research Centre, Mumbai, India, Tel: +91 022 66573343; E-mail: sonabnair@rediffmail.com

Key words: Prenatal diagnosis, Preimplantation genetic diagnosis, hemoglobinopathies

Received: March 28, 2018; Accepted: April 11, 2018; Published: April 13, 2018 
The details of all the cases of PND are shown in Table 1. The representative gel pictures for the PND and MCC are shown in Figures 1,2 and 3 respectively.

\section{Preimplantation Genetic Diagnosis (PGD)}

Unaffected embryo transfer after PGD was carried out in $3 / 4$ couples for $\beta$-thalassemia who opted for PGD.

Of these 1 couple (Trait for IVS 1-5 G>C) gave birth to a live healthy baby in 2015 . They had a second natural conception which was terminated due to detection of $\beta$-thalassemia major fetus after PND last year. The couple is undergoing next frozen embryo transfer cycle for second child using their remaining PGD tested unaffected embryos.

Another couple who were carriers for $619 \mathrm{bp}$ deletion mutation who opted for PGD had a normal embryo transfer and the pregnancy is ongoing.

The embryo transfer has been also carried out for 1 couple with Sickle cell trait and another couple carrier for Hemochromatosis. The pregnancy results are still awaited.

Table 1. Shows the details of all PND cases

\begin{tabular}{|c|c|c|c|}
\hline Mutation in Father & Mutation in Mother & Mutation in Fetus & Fetal Status \\
\hline $619 b p$ del & $\mathrm{CD} 15(\mathrm{G} \rightarrow \mathrm{A})$ & $\begin{array}{c}\text { 619bp del + } \\
\text { CD15(G } \rightarrow \mathrm{A})\end{array}$ & Affected \\
\hline $619 b p$ del & $619 b p$ del & $619 b p$ del $+619 b p$ del & Affected \\
\hline $\mathrm{CD} 8 / 9(+\mathrm{G})$ & $619 b p$ del & Absent & Normal \\
\hline $\mathrm{IVS} 1 \rightarrow 5(\mathrm{G} \rightarrow \mathrm{C})$ & IVS1 $\rightarrow 5(\mathrm{G} \rightarrow \mathrm{C})$ & $\begin{array}{c}\mathrm{IVS} 1 \rightarrow 5(\mathrm{G}->\mathrm{C})+ \\
\mathrm{IVS} 1 \rightarrow 5(\mathrm{G}->\mathrm{C})\end{array}$ & Affected \\
\hline $\mathrm{CD} 8 / 9(+\mathrm{G})$ & $619 b p$ del & Absent & Normal \\
\hline $\mathrm{CD} 8 / 9(+\mathrm{G})$ & $619 b p$ del & $\mathrm{CD} 8 / 9(+\mathrm{G})+619 \mathrm{bp}$ del & Affected \\
\hline $619 \mathrm{bp}$ del & $\mathrm{CD} 8 / 9(+\mathrm{G})$ & $\begin{array}{l}\text { 619bp del }+ \\
\mathrm{CD} 8 / 9(+\mathrm{G})\end{array}$ & Affected \\
\hline $619 b p$ del & $619 b p$ del & Absent & Normal \\
\hline $\mathrm{CD} 6 \mathrm{~A} \rightarrow \mathrm{T}$ & $\mathrm{CD} 6 \mathrm{~A} \rightarrow \mathrm{T}$ & $\mathrm{CD} 6 \mathrm{~A} \rightarrow \mathrm{T}$ & Trait \\
\hline
\end{tabular}

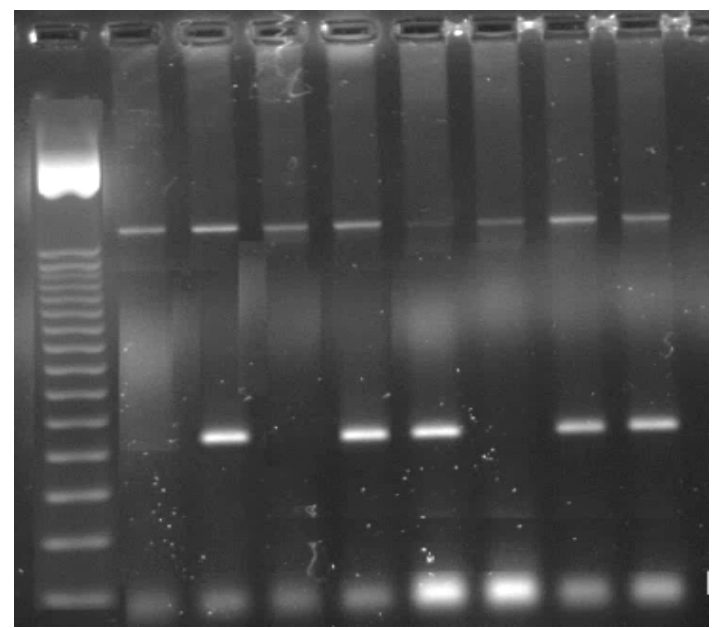

Figure 1. PND in an IVS1-5 $(\mathrm{G} \rightarrow \mathrm{C})$ carrier couple showing an affected fetus $1=50 \mathrm{bp}$ Ladder,

$2=$ CVS IVS1 $-5(\mathrm{G}->\mathrm{C})$ Normal

$3=$ CVS IVS1-5 $(\mathrm{G}->\mathrm{C})$ Mutant

$4=$ CVS IVS1-5 $(\mathrm{G}->\mathrm{C})$ Normal

$5=$ CVS IVS1-5 $(\mathrm{G}->\mathrm{C})$ Mutant

$6=$ Neg Cont IVS1-5 $(\mathrm{G}->\mathrm{C})$ Normal

$7=$ Neg Cont IVS1-5 (G->C) Mutant

$8=$ Pos. Cont IVS1-5 $(\mathrm{G}->\mathrm{C})$ Normal

$9=$ Pos Cont IVS1-5 (G->C) Mutant

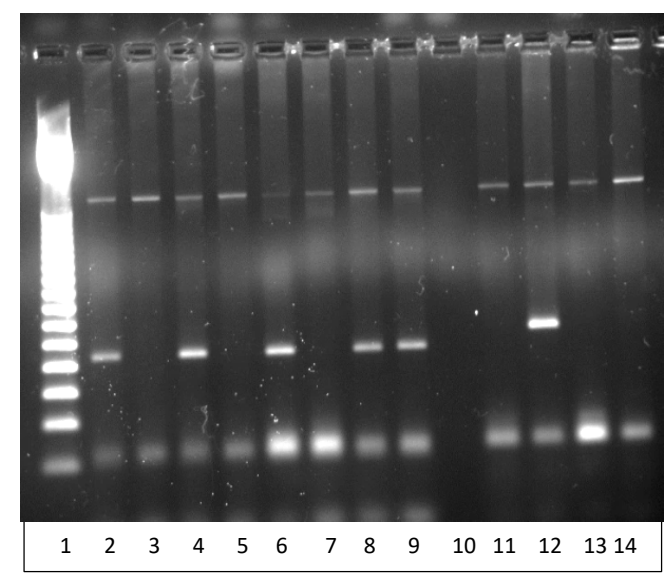

Figure 2. PND in a carrier couple with 619 bp deletion in mother and CD $8 / 9(+\mathrm{G})$ in father showing an unaffected normal fetus.

$1=50 \mathrm{bp}$ Ladder

$2=\mathrm{CVSCD} 8 / 9(+\mathrm{G})$ Normal

$3=\mathrm{CVS} \mathrm{CD} 8 / 9(+\mathrm{G})$ Mutant

$4=\mathrm{CVS} \mathrm{CD} 8 / 9(+\mathrm{G})$ Normal

$5=$ CVS CD8/9 $(+\mathrm{G})$ Mutant

$6=$ Neg. Cont. CD8/9 $(+\mathrm{G})$ Normal

$7=$ Neg. Cont. CD8/9 $(+\mathrm{G})$ Mutant

$8=$ Pos. Cont. CD8/9 $(+\mathrm{G})$ Normal

$9=$ Pos. Cont. CD8/9 $(+\mathrm{G})$ Mutant

$10=$ Blank

$11=$ CVS 619bp del

$12=$ Pos. Cont. $619 \mathrm{bp}$ del

$13=$ Neg. Cont. $619 \mathrm{bp}$ del

$14=$ CVS 619 bp del

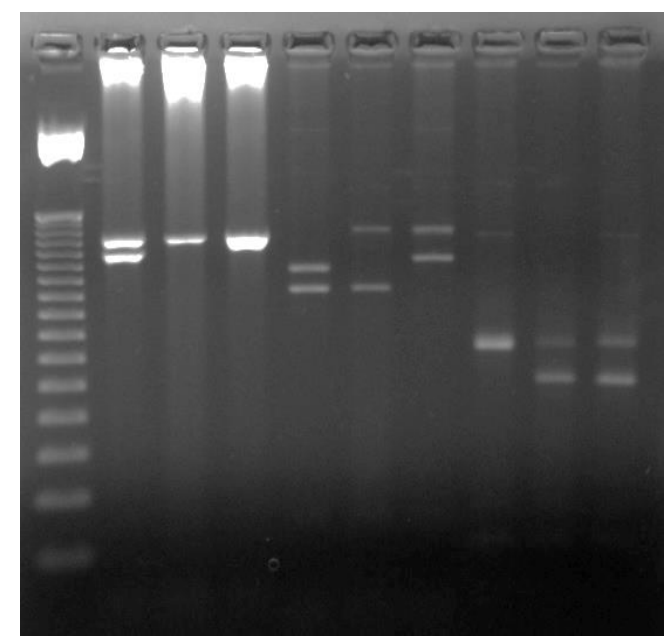

Figure 3. MCC testing using VNTR markers in a couple undergoing PND showing absence of MCC with D1S80 marker. Other markers were uninformative

$1=50 \mathrm{bp} \mathrm{Ladder}$

$2=$ Father Apo B

$3=$ CVS Apo B

$4=$ Mother Apo B

$5=$ Father D1S80

$6=$ CVS D1S 80

$7=$ Mother D1S80

$8=$ Father ACT BP2

$9=$ CVS ACT BP2

$10=$ Mother ACT BP2 


\section{Conclusion}

PND and PGD are two important options to prevent the birth of an affected child with hematological disorder. Prenatal diagnosis and subsequent termination of pregnancy if the fetus is found to be affected with the disorder may not be acceptable to every carrier couple due to emotional trauma involved or due to religious and cultural beliefs. PGD is another approach which can help the couple to have an unaffected child in cases of thalassemia, sickle cell anemia and other hematological disorders when the parental carrier status is already identified before pregnancy and if the couples do not want to go through the trauma of pregnancy termination after PND.

PGD also helps in creation of a "savior sibling" which involves the selection of an HLA matched unaffected embryo via PGD. This child when born serves as a "savior sibling" for the affected child needing a transplant by providing umbilical cord stem cells or bone marrow to an older sibling having the disorder.

Genetic counseling is extremely important to create awareness about the disorder and to stress upon the importance of PND or PGD as well as testing the extended family members of the affected individual or a carrier to prevent it from spreading to next generation.

\section{Conflicts of interest}

The authors declare that they have no conflict of interest.

\section{Ethical approval}

All procedures performed in studies involving human participants were in accordance with the ethical standards of the institutional and national research committee.

\section{Informed consent}

Informed consent was obtained from all individual participants included in the study.

\section{Acknowledgement}

The authors thank Jaslok Hospital and Research Centre for their Laboratory support.

\section{References}

1. Weatherall DJ, Clegg JB (2001) Inherited hemoglobin disorders: an increasing global health problem. Bull World Health organ 79: 704-712. [Crossref]

2. Weatherall DJ (2010) The inherited diseases of hemoglobin are an emerging global health burden. Blood 115: 4331-4336. [Crossref]

3. Thacker N (2007) Prevention of thalassemia in India. Indian Pediatrics 44:6 47-648 [Crossref]

4. Mohanty D, Colah RB, Gorakshakar AC, Patel RZ, Master DC et al (2013) Prevalence of $\beta$-thalassemia and other hemoglobinopathies in six cities in India: A multicentre study. J Community Genet 4: 33-42. [Crossref]

5. Monni G, Peddes C, Iuculano A, Ibba RM (2018) From prenatal to preimplantation genetic diagnosis of $\beta$ - thalassemia. Prevention Model in 8748 cases: 40 years of single center experience. Journal of Clinical Medicine 7: 35 [Crossref]

6. Dong-Zhi Li, Yang-Dong Yang (2017) Invasive prenatal diagnosis for fetal thalassemia. Gynecology 39: 41-52.

7. Athalye AS, Madon PF, Parikh FR (2015) Preimplantation Genetic Diagnosis for Single Gene Disorders. In: Hematology Today 2015 - a case-based approach. Ed: Agarwal MB 12: 125-128.

8. Monk M, Holding C (1990) Amplification of a $\beta$-hemoglobin sequence in individual human oocytes and polar bodies. Lancet 325: 985-988. [Crossref]

9. Monni G, Cau G, Usai V, Perra G, Lai R et al (2004) Preimplantation genetic diagnosis for beta-thalassemia: the Sardinian experience. Prenat Diagn 24: 949-954. [Crossref]

10. Orofino MG, Argiolu F, Sanna MA, Rosatelli MC, Tuveri T et al (2003) Fetal HLA typing in beta thalassemia: implications for haemopoietic stem-cell transplantation. Lancet 362: 41 - 42. [Crossref]

11. Fiorentino F, Kahraman S, Karadayi H, Biricik A, Sertyel S et al (2005) Short tandem repeats haplotyping of the HLA region in preimplantation HLA matching. Eur J Hum Genet 13: 953-9518. [Crossref]

Copyright: (C2018 Nair SB. This is an open-access article distributed under the terms of the Creative Commons Attribution License, which permits unrestricted use, distribution, and reproduction in any medium, provided the original author and source are credited. 